\title{
BJO
}

\section{Emergence of diplopia and oscillopsia due to Heimann-Bielschowsky phenomenon after cataract surgery}

S-H Jeong, Y-M Oh, J-M Hwang, et al.

Br J Ophthalmol 2008 92: 1402

doi: 10.1136/bjo.2007.135624

Updated information and services can be found at:

http://bjo.bmj.com/content/92/10/1402

These include:

Supplemental http://bjo.bmj.com/content/suppl/2008/09/26/92.10.1402.DC1.html Material

Email alerting Receive free email alerts when new articles cite this article. Sign up in the service box at the top right corner of the online article.

Notes

To order reprints of this article go to:

http://bjo.bmj.com/cgi/reprintform

To subscribe to British Journal of Ophthalmology go to:

http://bjo.bmj.com/subscriptions 
36. Chayet AS, Assil KK, Montes M, et al. Regression and its mechanisms after laser in situ keratomileusis in moderate and high myopia. Ophthalmology 1998;105:1194-9.

37. Lohmann CP, Guell JL. Regression after LASIK for the treatment of myopia: the role of the corneal epithelium. Semin Ophthalmol 1998;13:79-82.

38. Hjortdal J0, Moller-Pedersen T, Ivarsen A, et al. Corneal power, thickness, and stiffness: results of a prospective randomized controlled trial of PRK and LASIK for myopia. J Cataract Refract Surg 2005;31:21-9.

39. Erie JC, Nau CB, McLaren JW, et al. Long-term keratocyte deficits in the corneal stroma after LASIK. Ophthalmology 2004;111:1356-61.

40. Mitooka K, Ramirez M, Maguire LJ, et al. Keratocyte density of central human cornea after laser in situ keratomileusis. Am J Ophthalmol 2002;133:307-14.

41. Adrain C, Brumatti G, Martin SJ. Apoptosomes: protease activation platforms to die from. Trends Biochem Sci 2006;31:243-7.
42. Wilson SE. Analysis of the keratocyte apoptosis, keratocyte proliferation, and myofibroblast transformation responses after photorefractive keratectomy and laser in situ keratomileusis. Trans Am Ophthalmol Soc 2002;100:411-33.

43. Dawson DG, Holley GP, Geroski DH, et al. Ex vivo confocal microscopy of human LASIK corneas with histologic and ultrastructural correlation. Ophthalmology 2005; 112:634-44.

44. Calvillo MP, McLaren JW, Hodge DO, et al. Corneal reinnervation after LASIK: prospective 3-year longitudinal study. Invest Ophthalmol Vis Sci 2004;45:3991-6.

45. Patel DV, McGhee CN. Mapping of the normal human corneal sub-basal nerve plexus by in vivo laser scanning confocal microscopy. Invest Ophthalmol Vis Sci 2005;46:4485-8.

46. Tervo T, Vannas A, Tervo K, et al. Histochemical evidence of limited reinnervation of human corneal grafts. Acta Ophthalmol 1985;63:207-14.

\title{
Video report
}

\section{Emergence of diplopia and oscillopsia due to Heimann- Bielschowsky phenomenon after cataract surgery}

\begin{abstract}
The Heimann-Bielschowsky phenomenon (HBP) refers to coarse vertical oscillation of the eye with impaired vision. The ocular movements are strictly monocular, occurring only in the eye with amblyopia. The vertical oscillation is of equal velocity in both vertical directions, or may sometimes be greater in the downward than upward direction. HBP develops several years after loss of vision. It can be differentiated from dissociated nystagmus in spasmus nutans, congenital nystagmus and internuclear ophthalmoplegia based on the strict unilaterality, vertical direction and low frequency. Previously, only a few reports described the development of oscillopsia due to HBP after cataract surgery, which resolved spontaneously or responded to gabapentin. However, visual impairments due to diplopia or oscillopsia from HBP after cataract surgery have received little attention. We report a man who developed persistent vertical diplopia and oscillopsia due to HBP after a cataract operation, which markedly impaired his vision.

- To view the full report and accompanying video please go to: http://bjo.bmj.com/cgi/content/full/92/10/1402/DC1

- All videos from the BJO video report collection are available from: http://bjo.bmj.com/video/collection.dtl

\section{S-H Jeong ${ }^{1}$, Y-M Oh' ${ }^{1}$ J-M Hwang ${ }^{2}$, J S Kim ${ }^{1}$}

${ }^{1}$ Department of Neurology, College of Medicine, Seoul National University, Seoul National University Bundang Hospital, Gyeonggi-do, Korea; ${ }^{2}$ Department of Ophthalmology, College of Medicine, Seoul National University, Seoul National University Bundang Hospital, Gyeonggi-do, Korea
\end{abstract}

Correspondence to: J S Kim, Department of Neurology, Seoul National University Bundang Hospital, 300 Gumi-dong, Bundanggu, Seongnam-si, Gyeonggi-do, 463-707, Korea; jisookim@snu.ac.kr

Funding: JSK was supported by the second stage Brain Korea 21 Project in 2006.

Competing interests: None.

Br J Ophthalmol 2008;92:1402. doi:10.1136/bjo.2007.135624 